\title{
Ação de Inseticidas Botânicos sobre a Preferência Alimentar e sobre Posturas de Spodoptera frugiperda (J.E. Smith) (Lepidoptera: Noctuidae) em Milho*
}

\author{
Fábio Mazzonetto ${ }^{\bowtie}$, Flávia Coradini, Renato Zapparoli Corbani \& Alexandre Barcellos Dalri
}

Universidade Camilo Castelo Branco, e-mail: coord.agronomia.des@unicastelo.br (Autor para correspondência ${ }^{\bowtie}$ ), flacoradini@hotmail.com, renatozapparoli@hotmail.com, abdalri@uol.com.br.

\section{EntomoBrasilis 6 (1): 34-38 (2013)}

Resumo. O presente trabalho objetivou comparar o efeito de diferentes extratos de origem vegetal na preferência alimentar e na postura da lagarta do cartucho Spodoptera frugiperda (J.E. Smith) em folhas de milho. Extratos aquosos a 10\% p/v de Chenopodium ambrosioides (Linnaeus) (Erva de Santa Maria), Corymbia citriodora (Hill \& Johnson) (Eucalipto Cheiroso), Chrysanthemum leucanthemum (Linnaeus) (Crisântemo) e Azadirachta indica (A. Juss) (Nim) foram aplicados em discos de folhas de milho e oferecidos às lagartas em testes com e sem chance de escolha. A atratividade das lagartas pelos discos com os extratos não diferiu da testemunha no teste com chance de escolha, porém os extratos de Nim e Crisântemo apresentaram efeito fagodeterrente a $S$. frugiperda. Nos testes sem chance de escolha, o tratamento que mais repeliu as lagartas foi utilizando extrato de Nim, representando possível alternativa para o controle das lagartas desta espécie. Nenhum dos extratos aquosos das espécies vegetais testadas apresentou efeito ovicida.

Palavras-chaves: Extratos Vegetais; Lagarta do Cartucho; Zea mays.

\section{Action of Botanical Insecticides on the Preference of Food and on Postures of Spodoptera frugiperda (J.E. Smith) (Lepidoptera: Noctuidae) in Maize}

Abstract. This study compares the effect of different extracts of vegetal origin in food preference and posture of the fall armyworm Spodoptera frugiperda (J.E. Smith) in maize leaves. Aqueous extracts $10 \% \mathrm{w} / \mathrm{v}$ of Chenopodium ambrosioides (Linnaeus), Corymbia citriodora (Hill \& Johnson), Chrysanthemum leucanthemum (Linnaeus) and Azadirachta indica (A. Juss) were applied to leaf discs of maize and offered to caterpillars tests with and without choice. The attractiveness of the caterpillars for discs with the extracts did not differ from the control test-choice, but extracts of $A$. indica and $C$. leucanthemum showed antifeedant activity to $S$. frugiperda. In no-choice tests, the treatment was more repelled the larvae using $A$. indica extract, representing possible alternative for the control of caterpillars of this species. None of the aqueous extracts of the plant species tested showed ovicidal effect.

Keywords: Fall Armyworm; Vegetal Extracts; Zea mays.

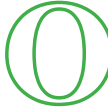
milho é cultivado no Brasil em aproximadamente 14 milhões de hectares, com produção de aproximadamente 51,3 milhões de toneladas por ano e produtividade média de 3,6 toneladas por hectare (CONAB 2010). Pode ser encontrado no mercado interno para consumo humano ainda na espiga ou já processado (grão enlatado, curau, mingau), sendo, no entanto, a maior parte de sua produção destinada à alimentação de aves, suínos e bovinos (Agriandal 2007). Apresenta expressiva importância como matéria prima para o uso industrial (LiMA et al. 2009).

Apesar de estar entre os três maiores produtores, o Brasil não se destaca entre os países com maior produtividade. $\mathrm{O}$ milho, mesmo sendo cultivado praticamente em todo o mundo e, embora apresente alta produtividade, sofre o ataque de várias espécies de insetos praga (MARTINAZzo et al. 2007).

A lagarta do cartucho, Spodoptera frugiperda (J.E. Smith), é uma das mais importantes pragas da cultura do milho. A redução na produtividade do milho, devido ao ataque desta praga, depende do grau de infestação e estádio de desenvolvimento da planta (LoURENÇão \& SANTOS 2005), podendo atingir 60\% dependendo da cultivar e época em que o ataque ocorre (CRUz et al. 2009).
De acordo com Carvalho et al. (2008), inseticidas químicos têm sido empregados na agricultura com frequência e relativo sucesso, no entanto, podem provocar contaminação ambiental, presença de resíduos nos alimentos, efeitos prejudiciais sobre inimigos naturais e seleção de populações de insetos resistentes.

O controle de pragas com a utilização de métodos de controle alternativos, especificamente com extratos vegetais, vem sendo estudado para minimizar o uso de inseticidas químicos. Tais métodos podem favorecer principalmente o pequeno agricultor, já que são de fácil utilização, não exigindo pessoal qualificado, são mais baratos e não afetam o meio ambiente, além de poderem ser produzidos na própria propriedade, facilitando a sua utilização (MazzonetTo \& VendRAmim 2003).

Este trabalho teve como objetivo comparar o efeito de diferentes extratos de origem vegetal na preferência alimentar e na postura de lagarta do cartucho, $S$. frugiperda, em folhas de milho.

\section{*Este trabalho foi financiado pelo Conselho Nacional de} Desenvolvimento Científico e Tecnológico - CNPq 


\section{MATERIAL E MÉTODOS}

Os experimentos foram conduzidos no Laboratório de Fitotecnia da Universidade Camilo Castelo Branco, Campus de Descalvado/ $\mathrm{SP}$ e os ensaios realizados em câmara incubadora à temperatura de $25 \pm 2^{\circ} \mathrm{C}$, umidade relativa de $60 \pm 10 \%$ e fotofase de 14 horas.

Para realização dos bioensaios foram mantidas criaçõesestoque de lagarta do cartucho, $S$. frugiperda, em dieta artificial modificada seguindo a metodologia proposta por GreENE et al. (1976) (Tabela 1).

Tabela 1. Composição da dieta modificada de GreEne et al. (1976).

\begin{tabular}{lc}
\hline \multicolumn{1}{c}{ Constituinte } & Quantidade \\
\hline Feijão branco & $75,00 \mathrm{~g}$ \\
Germe de trigo & $60,00 \mathrm{~g}$ \\
Farelo de soja & $30,00 \mathrm{~g}$ \\
\hline Leite em pó & $30,00 \mathrm{~g}$ \\
\hline Levedura de cerveja & $37,50 \mathrm{~g}$ \\
Ácido ascórbico & $3,60 \mathrm{~g}$ \\
\hline Ácido sórbico & $1,80 \mathrm{~g}$ \\
Nipagin & $3,00 \mathrm{~g}$ \\
\hline Solução vitamínica & $9,00 \mathrm{~mL}$ \\
Tetraciclina & $0,12 \mathrm{~g}$ \\
Formaldeído (40\%) & $3,60 \mathrm{~mL}$ \\
Agar & $23,00 \mathrm{~g}$ \\
Água & $1400,00 \mathrm{~mL}$ \\
\hline
\end{tabular}

Os materiais vegetais testados foram provenientes de coleta na área experimental do C.E.U - Centro Experimental da Unicastelo, Campus de Descalvado/SP. Foram testadas as seguintes plantas:

- Erva de Santa Maria - Chenopodium ambrosioides (Linnaeus): utilizando-se parte aérea;

- Eucalipto cheiroso - Corymbia citriodora (Hill \& Johnson): utilizando-se folhas;

- Crisântemo - Chrysanthemum leucanthemum (Linnaeus): utilizando-se folhas;

- Nim - Azadirachta indica (A. Juss): utilizando-se folhas.

As partes utilizadas de cada planta foram secas em estufa a $40^{\circ} \mathrm{C}$, por $48 \mathrm{~h}$, posteriormente trituradas em moinho de facas, até obtenção de pó e armazenado em vidros hermeticamente fechados.

Os preparo dos extratos foi realizado pela imersão de $10 \mathrm{~g}$ do pó em $100 \mathrm{~mL}$ de água destilada, agitação para homogeneização da amostra durante $2 \mathrm{~h}$ em câmara agitadora, manutenção em repouso por $24 \mathrm{~h}$ em geladeira para extração dos compostos hidrossolúveis. Após esse período, filtrou-se o material em tecido fino tipo voil para retirada do material sólido, obtendo-se, assim, extratos aquosos a 10\% p/v de cada espécie vegetal. Os extratos prontos foram utilizados em um período não superior à $24 \mathrm{~h}$ após o preparo.

As plantas de milho foram cultivadas em vasos plásticos de $8 \mathrm{~L}$ de capacidade em casa de vegetação com tratos culturais recomendados para a cultura. Realizou-se a adubação de plantio de acordo com a análise de solo tendo como parâmetro o Boletim IAC 100. Aos 30 dias após emergência das plântulas foi realizada a adubação de cobertura de acordo com a necessidade da cultura.

Para utilização nos bioensaios laboratoriais, foi dada preferência para a colheita da terceira folha pós-emergida das plantas de milho.
Testes sobre a preferência alimentar de $\boldsymbol{S}$. frugiperda. Para cada extrato, foram realizados dois testes: um com chance de escolha entre substrato (folha de milho tratada com extrato e não tratada) e outro sem chance de escolha apenas entre substratos tratados com o mesmo extrato. Estes testes tiveram como objetivo determinar se o extrato tem ação fagoestimulante ou fagodeterrente sobre o inseto.

a. Teste com chance de escolha. Para este ensaio, foram utilizadas placas de Petri de $15 \mathrm{~cm}$ de diâmetro, com o fundo recoberto por papel filtro levemente umedecido com água destilada. Sobre o papel, foram colocados discos de folhas de milho de $1,6 \mathrm{~cm}$ de diâmetro, obtidos com vazador. Foram colocados quatro discos por placa, sendo dois tratados com extratos e dois com água destilada, dispostos aos pares de forma cruzada e equidistantes. Cada disco foi identificado por uma letra escrita abaixo da placa. No centro de cada placa foi liberada uma lagarta de $5^{\circ}$ ínstar (caracterizadas na criação estoque pela cápsula cefálica). Após duas horas, as lagartas foram retiradas e a área dos discos foi medida com o auxílio do software ImageJ 1.45S (National Institute of Health). O consumo foliar, por inseto, foi obtido pela diferença entre a área inicial da folha e a área que restou após a alimentação das lagartas. Para cada tratamento foram utilizados 10 placas, cada uma representando uma repetição.

Para este teste, o delineamento estatístico foi inteiramente casualizado e os dados obtidos foram analisados estatisticamente pelo teste F e as médias comparadas pelo teste de "t" de Student a $5 \%$ de probabilidade.

O efeito produzido pelo extrato vegetal foi avaliado utilizando o índice de preferência alimentar de Kogan \& GoEden (1970), sendo classificado como fagoestimulante se o índice for maior do que 1 , neutro se igual a 1 e fagodeterrente se menor do que 1 , através da fórmula:

$$
\mathrm{IP}=2 \mathrm{~A} /(\mathrm{M}+\mathrm{A}), \text { onde: }
$$

$\mathrm{A}$ = área consumida dos discos tratados;

$\mathrm{M}$ = áreas consumidas dos discos não tratados.

b. Teste sem chance de escolha. Este ensaio foi desenvolvido da mesma forma que o anterior, apenas com a diferença de aplicar o mesmo tratamento (extrato vegetal) nos quatro discos em cada exposição às lagartas. Para cada tratamento foram utilizados 10 placas, cada uma representando uma repetição.

Para este teste, o delineamento estatístico foi inteiramente casualizado e os dados obtidos foram analisados estatisticamente pelo teste $\mathrm{F}$ e as médias comparadas pelo teste de Tukey a $5 \%$ de probabilidade.

\section{Testes sobre as posturas de $S$. frugiperda}

Ovos oriundos das gaiolas onde foi mantida a criação estoque de $S$. frugiperda, foram colocados em placas de Petri. Sobre os ovos foram aplicados os extratos das diferentes espécies vegetais $(10 \% \mathrm{p} / \mathrm{v})$ e água destilada no controle testemunho. No quinto dia após a aplicação nos tratamentos, procedeu-se à contagem do número de lagartas eclodidas em cada placa, para a determinação da viabilidade de ovos. Para cada extrato foram utilizadas cinco placas com 20 ovos em cada placa, cada uma representando uma repetição, ou seja, totalizando 5 repetições.

Para este teste, o delineamento estatístico foi inteiramente casualizado e os dados obtidos foram analisados estatisticamente pelo teste $\mathrm{F}$ e as médias comparadas pelo teste de Tukey a $5 \%$ de probabilidade. 


\section{RESULTADOS E DISCUSSÃO}

\section{Testes sobre a preferência alimentar de $S$. frugiperda}

a. Teste com chance de escolha. A atratividade das lagartas pelos discos de folhas de milho tratados com os diferentes extratos aquosos, não diferiu estatisticamente da testemunha no teste com chance de escolha (Tabela 2). No entanto, quando se utilizou o Índice de Preferência (IP) proposto por Kogan \& Goeden (1970), onde se caracteriza o extrato vegetal como fagoestimulante se $o$ índice for maior do que 1 , neutro se igual a 1 e fagodeterrente se menor do que 1, mesmo não diferindo estatisticamente, os extratos vegetais de Nim e Crisântemo demonstraram causar um efeito fagodeterrente sobre $S$. frugiperda, com IP de - 0,78 e - o,61, respectivamente, reduzindo a atividade alimentar das lagartas, o que pode resultar em diminuição dos danos causados às plantas e consequentes prejuízos ocasionados por essa praga.

Uma das atividades mais relevantes das plantas da família Meliaceae é a ação fagoinibidora (VIVAN 2009), o que foi observado nos testes com chance de escolha (Tabela 2) com o extrato a partir de folhas de Nim.

Resultados semelhantes utilizando a planta de Nim, porém com o produto comercial DalNeem (5 e 10\%) foram obtidos por BIERMANN (2009) que, em testes com chance de escolha ao avaliarem o efeito da aplicação, em couve, na alimentação de lagartas de Ascia monuste orseis (Latreille), verificaram que, apesar de estatisticamente não deferir da testemunha, apresentaram Índices de Preferência (IP) menor que 1, sendo classificada como fagodeterrente.

Assim, os resultados obtidos mostraram que os extratos vegetais de Nim e Crisântemos proporcionaram leve ação fagodeterrente aos insetos, quando os discos tratados com seus extratos foram oferecidos às lagartas de $S$. frugiperda.

b. Teste sem chance de escolha. De acordo com os dados encontrados com os testes onde as lagartas não tiveram chance de escolha entre o milho tratado com extrato ou não tratado (Figura 1), pode-se observar que os extratos de Erva de Santa Maria, Eucalipto Cheiroso e Crisântemo não apresentaram diferença estatisticamente significativa em relação à testemunha. $\mathrm{O}$ tratamento que resultou em repelência mais acentuada às lagartas foi com a utilização do extrato a base de Nim, que deferiu da testemunha estatisticamente, concordando os resultados com o que foram expostos por Aguiar-Menezes (2005), quando menciona que os lepidópteros são extremamente sensíveis à azadiractina presente no Nim.

Segundo dados obtidos por BiermanN (2009), os tratamentos que resultaram em repelência mais acentuada a lagartas de $A$. monuste orseis quando utilizou-se DalNeem a 10\%, comprovando a ação desta planta sobre lepidópteros.

\section{Testes sobre as posturas de $S$. frugiperda}

A análise do efeito dos extratos aquosos das diferentes espécies vegetais aplicados sobre ovos de $S$. frugiperda (Tabela 3), demonstrou que não houve diferênça estatística entre os

Tabela 2. Média das áreas dos discos foliares de milho consumidos por Spodoptera frugiperda tratados com os diferentes extratos aquosos a 10\% (p/v), em teste com chance de escolha. Temp.: $25 \pm 2^{\circ} \mathrm{C}$, UR: $60 \pm 10 \%$ e fotofase: 14 horas.

\begin{tabular}{|c|c|c|c|c|}
\hline \multirow[b]{2}{*}{ Extratos Vegetais $10 \%(p / v)$} & \multicolumn{2}{|c|}{ Área Consumida $\left(\mathrm{cm}^{2}\right)$} & \multirow{2}{*}{$\begin{array}{c}\text { Índice de } \\
\text { Preferência }^{2}\end{array}$} & \multirow[b]{2}{*}{ Classificação $^{2}$} \\
\hline & $\begin{array}{c}\text { Discos foliares } \\
\text { tratados }^{1}\end{array}$ & $\begin{array}{c}\text { Discos foliares } \\
\text { não tratados }\end{array}$ & & \\
\hline C. ambrosioides (Erva de Santa Maria) & $0,230 \mathrm{a}$ & 0,124 a & $+1,29$ & Fagoestimulante \\
\hline C. citriodora (Eucalipto Cheiroso) & 0,213 a & 0,189 a & $+1,06$ & Fagoestimulante \\
\hline A. indica (Nim) & 0,079 a & 0,124 a & $-0,78$ & Fagodeterrente \\
\hline Chrysanthemum sp. (Crisântemo) & 0,082 a & 0,187 a & $-0,61$ & Fagodeterrente \\
\hline
\end{tabular}

${ }^{1}$ Médias seguidas pela mesma letra, nas linhas, não diferem significativamente pelo teste de " $\mathrm{t}$ " de Student a $5 \%$ de probabilidade.

${ }^{2} \mathrm{IP}=2 \mathrm{~A} /(\mathrm{M}+\mathrm{A})$; onde $\mathrm{A}$ = área consumida dos discos tratados; $\mathrm{e}, \mathrm{M}$ = áreas consumidas nos discos não tratados. Classificação: fagoestimulante se o índice for maior do que 1 ; neutro se igual a 1 e fagodeterrente se menor do que 1.

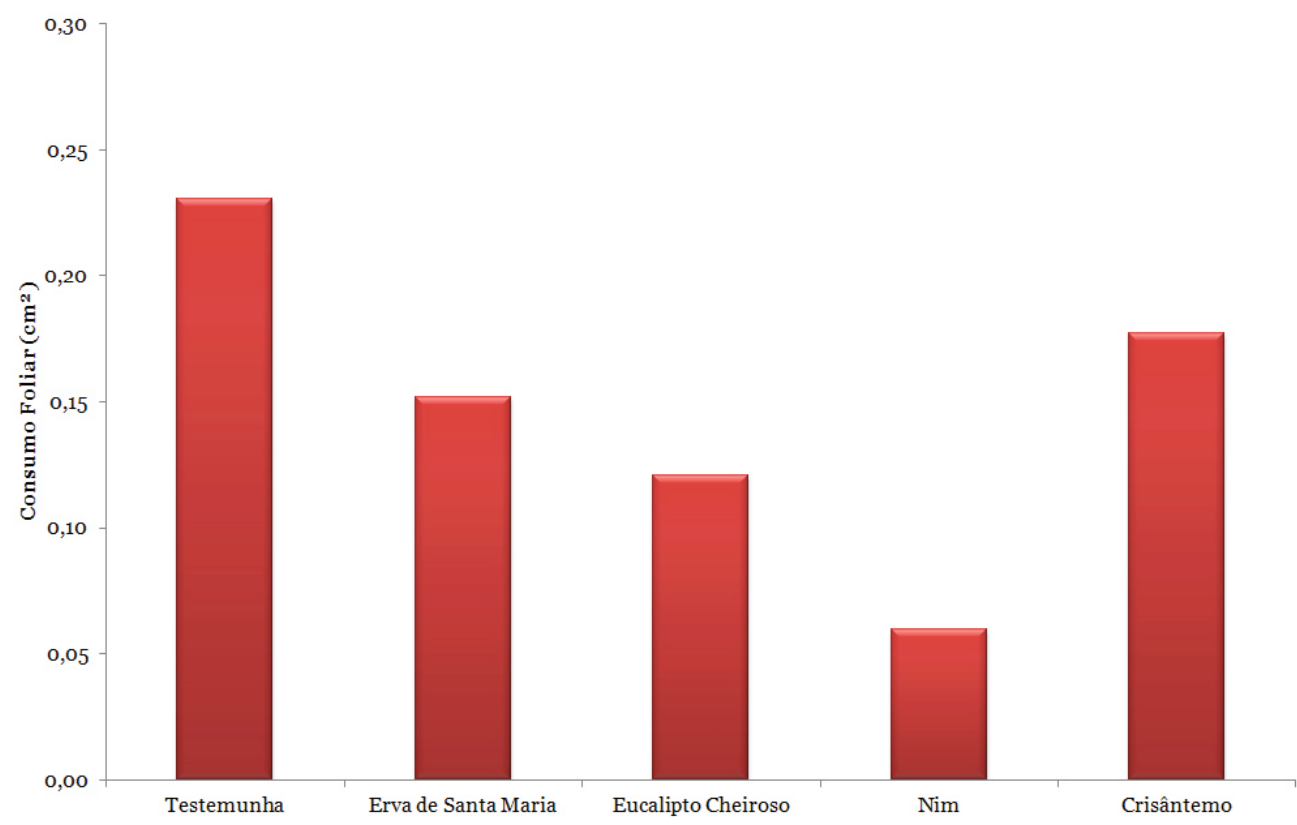

Figura 1. Consumo Foliar médio $\left(\mathrm{cm}^{2}\right)$, por lagartas de Spodoptera frugiperda, de discos foliares de milho tratadas com extratos aquosos de diferentes espécies vegetais, em teste sem chance de escolha. Temp.: $25 \pm 2^{\circ} \mathrm{C}$, UR: $60 \pm 10 \%$ e fotofase: 14 horas. Médias seguidas pela mesma letra não diferem significativamente pelo teste de Tukey a $5 \%$. 
Tabela 3. Ação de diferentes extratos aquosos a 10\% (p/v) sobre ovos de Spodoptera frugiperda. Temp.: $25 \pm 2{ }^{\circ} \mathrm{C}$, UR: $60 \pm 10 \%$ e fotofase: 14 horas.

Extratos Vegetais 10\% (p/v)

Eclosão larval (\%)

Testemunha (Água destilada)

100,00 a

C.ambrosioides (Erva de Santa Maria)

C. citriodora (Eucalipto Cheiroso)

95,00 a

A. indica (Nim)

91,67 a

86,67 a

86,67 a

Chrysanthemum sp. (Crisântemo)

\begin{tabular}{lc} 
Teste F & $0,7800^{\text {ns }}$ \\
DMS & $\mathbf{3 0 . 0 8 0 1 7}$ \\
CV(\%) & 12,15 \\
\hline
\end{tabular}

Médias seguidas pela mesma letra não diferem significativamente pelo teste de Tukey a $5 \%$.

tratamentos, incluindo a Testemunha. A porcentagem de larvas eclodidas variou de 100\% (Testemunha) e 86,67\% (extrato aquoso de Crisântemo).

Os efeitos de extratos de plantas na sobrevivência da fase embrionária de lepidópteros são pouco conhecidos, em especial a ação ovicida dos compostos bioativos (Prédes et al. 2000). MACHADO et al. (2007) destacaram que o efeito ovicida pode variar de acordo com a espécie do inseto e com as características das substâncias utilizadas. Porém, este mesmo autor menciona que plantas com atividade inseticida ocasionam baixo ou nenhum efeito sobre os ovos. Tal fato pode ser verificado no experimento realizado com os diferentes extratos aquosos sobre a porcentagem de lagartas eclodidas de $S$. frugiperda.

Pelos dados obtidos nas condições do experimento, pode-se concluir que:

- A atratividade das lagartas pelos discos com os extratos não diferiu da testemunha no teste com chance de escolha, porém os extratos de Nim e Crisântemo apresentaram efeito fagodeterrente a $S$. frugiperda.

- Nos testes sem chance de escolha, o tratamento que mais repeliu as lagartas foi utilizando extrato de Nim, representando possível alternativa para o controle das lagartas desta espécie.

- Nenhum dos extratos aquosos das espécies vegetais testadas apresentou efeito ovicida para $S$. frugiperda.

\section{REFERÊNCIAS}

Agrianual, 2007. Anuário da Agricultura Brasileira. São Paulo: FNP Consultoria e Comércio, 516p.

Aguiar-Menezes, E.L., 2005. Inseticidas Botânicos: Seus Princípios Ativos, Modo de Ação e Uso Agrícola. Seropédica: Embrapa Agrobiologia, 58p.

Biermann, A.C.S., 2009. Bioatividade de Inseticidas Botânicos sobre Ascia monuste orseis (Lepidoptera: Pieridae). Dissertação (Mestrado em Agronomia) - Universidade Federal de Santa Maria. 72p.

Carvalho, G.A., N.M. Santos, E.C. Pedroso \& A.F. Torres, 2008. Eficiência do óleo de nim (Azadirachta indica A. Juss) no controle de Brevicoryne brassicae (Linnaeus, 1758) e Myzus persicae (Sulzer, 1776) (Hemiptera: Aphididae) em couvemanteiga Brassica oleracea Linnaeus var. acephala. Arquivos do Instituto Biológico, 75: 181-186.

Conab - Companhia Nacional de Abastecimento, 2010. Série histórica. Comparativo de área, produção e produtividade.
Disponível em: http://www.conab.gov.br. Acesso em 12/07/2010.

Cruz, I., P.A. Viana \& J.M. Waquil, 2009. Pragas: pragas da fase vegetativa e reprodutiva. Sete Lagoas: Embrapa Milho e Sorgo. Disponível em: http://sistemasdeproducao.cnptia. embrapa.br/FontesHTML/Milho/CultivodoMilho 5ed/ prvegetativa.htm. Acesso em 25/07/2012.

Greene, G.L., N.C. Lepla \& W.A. Deckerson, 1976. Velvetbean caterpillar: a rearing procedure and artificial medium. Journal of Economic Entomolology, 69: 488-497.

Kogan, M. \& R.D. Goeden, 1970. The host-plant range of Lema trilineata daturaphila (Coleoptera: Chrysomelidae). Annals of Entomological Society of America, 63: 1175-1180.

Lima, M.P.L., J.V. Oliveira \& E.J. Marques, 2009. Manejo da lagarta do cartucho em milho com formulações de nim e Bacillus thuringiensis subsp. aizawai. Ciência Rural, 39: 1227-1230.

Lourenção, A.L.F. \& H.R. Santos, 2005. Danos de Spodoptera frugiperda (J.E.Smith, 1797) (Lepidoptera: Noctuidae) na cultura do milho (Zea mays L.). Revista de Agricultura, 80: 340-355.

Machado, L.A., V.B. Silva \& M.M. Oliveira, 2007. Uso de extratos vegetais no controle de pragas em horticultura. O Biológico, 69: 103-106.

Martinazzo, F., V. Pietrowski, E.S. Cordeiro, B. Eckstein \& S. Grisa, 2007. Liberação de Trichogramma pretiosum para controle biológico de Spodoptera frugiperda na cultura do milho. Revista Brasileira de Agroecologia, 2: 1657-166o.

Mazzonetto, F. \& J.D. Vendramim, 2003. Efeito de pós de origem vegetal sobre Acanthoscelides obtectus (Say) (Coleptera: Bruchidae) em feijão armazenado. Neotropical Entomology, 32: $145-149$.

Prédes, R.C., T.I.M.R. Marques, H.S. Xavier \& J.V. Oliveira, 2000. Extrato metanólico da amêndoa da semente de nim e a mortalidade de ovos e lagartas da traça-do-tomateiro. Scientia Agricola, 57: 407-413.

Vivan, M.P, 2009. Uso do cinamomo (Melia azedarach) como alternativa aos agroquímicos no controle do carrapato bovino (Boophilus microplus). Dissertação (Mestrado em Agroecossistemas) - Universidade Federal de Santa Catarina, $72 \mathrm{p}$.

\section{Recebido em: 24/07/2012}

Aceito em: 27/10/2012 


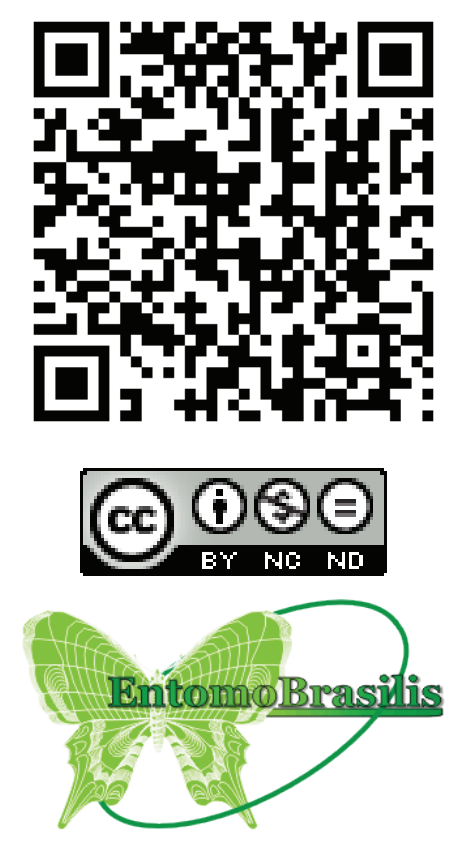

